\title{
HIV/Aids, Infant Mortality and Economic Growth: A Systematic Assessment of their Causal Relationship in Nigeria
}

\author{
Sede, Peter ${ }^{1}$ \\ Oghenerurie, Precious Uzezi ${ }^{2}$ \\ Abu, Prince Oshoke ${ }^{3}$ iD \\ Eniye, Blessing Adesuwa ${ }^{4}$ iD
}

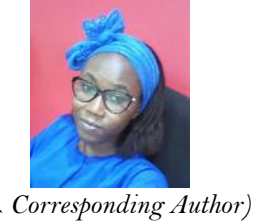

${ }^{2,3}$ Department of Economics, Faculty of Social Sciences, University of Benin, Benin City, Edo, Nigeria.

Email:p.petersede@gmail.com Tel: +2348131243666

Email:zeyzhee@gmail.comTel:+2347062498645

Email.princeoshokeabu@gmail.com Tel:+27739432113

'Access Bank Nigeria PLC, Nigeria.

${ }^{4}$ Email:eniyeblessing360@gmail.com Tel: +2347069648895

\section{Abstract}

Nigeria has the second largest HIV/AIDS burden in the world and this has been closely associated with adverse economic effects and in turn HIV/AIDS has hindered economic growth in the past decades. In this study, the Vector Error Correction Model was employed to investigate the relationship among HIV/AIDS, infant mortality and economic growth in Nigeria using time series data from 1980-2015. Mixed results were recorded as on one hand, HIV/AIDS impacts positively on infant mortality through Mother-To-Child-Transmission while on the other hand, economic growth was found to be positively correlated with HIV/AIDS. This is because, in most countries, including Nigeria, relatively rich and better educated men and women have higher rates of partner change. We therefore recommends that to achieve the desirable objective of sustainable economic growth, the health sector should be given a larger budgetary allocation and support as the current government expenditure on health is not making any significant impact.

Keywords: HIV/AIDS, Infant mortality, Economic Growth, Vector error correction model (VECM).

JEL Classification: I 10, I 15, F43, C22.

Citation | Sede, Peter; Oghenerurie, Precious Uzezi; Abu, Prince Oshoke; Eniye, Blessing Adesuwa (2020). HIV/Aids, Infant Mortality and Economic Growth: A Systematic Assessment of their Causal Relationship in Nigeria. Economy, 7(2): 87-97.

History:

Received: 13 April 2020

Revised: 25 May 2020

Accepted: 29 June 2020

Published: 20 July 2020

Licensed: This work is licensed under a Creative Commons

Attribution 3.0 License (cc)

Publisher: Asian Online Journal Publishing Group
Acknowledgement: All authors contributed to the conception and design of the study.

Funding: This study received no specific financial support

Competing Interests: The authors declare that they have no conflict of interests.

Transparency: The authors confirm that the manuscript is an honest, accurate, and transparent account of the study was reported; that no vital features of the study have been omitted; and that any discrepancies from the study as planned have been explained.

Ethical: This study follows all ethical practices during writing.

\section{Contents}

1. Introduction

2. Literature Review

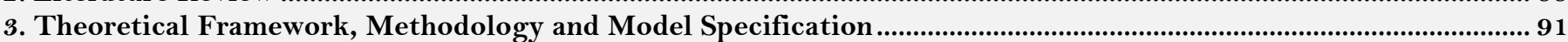

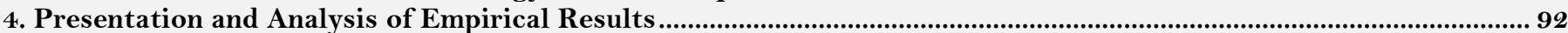

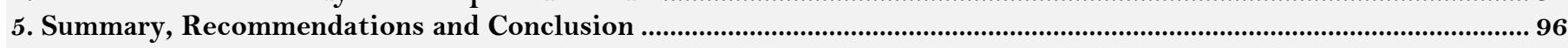

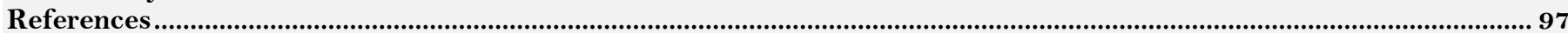




\section{Contribution of this paper to the literature}

The study is significant in the following respects. Firstly, the research provides an empirical analysis of the impact of HIV/AIDS and infant mortality on the Nigerian Gross Domestic Product (GDP). Since it is not based on just theoretical assessment, it provides the researcher and other concerned individuals the opportunity to evaluate the extent to which these factors and other health indicators have affected economic growth in Nigeria. Secondly, the study will serve as a literature for other individuals or organizations to make reference to in the nearest future. Finally, the study proffers solutions and recommendations that would be useful to the government, and agencies in formulating and implementing policies that would help in reducing the spread of HIV/AIDS and infant mortality to the barest minimum in the country.

\section{Introduction}

The first two cases of HIV in Nigeria were detected in 1985 and reported in 1986 at the International AIDS Conference in Lagos. The news of this first AIDS case sent panic, doubt and disbelief to the whole nation as AIDS was perceived as the disease of American homosexuals. The skepticism sold the impression of AIDS as a ploy by the Americans to discourage sex in Nigeria. This was exemplified in the emergence of various acronyms, one of which was 'American Idea for Discouraging Sex' (Awofala \& Ogundele, 2016; Eze, 2009). Up to six more were detected in 1987. This was when the Nigerian government decided to establish National AIDS Advisory Committee. The response by the Nigerian government to combat HIV/AIDS was very slow at the initial stage. The Federal Ministry of Health made its first real attempt to assess the AIDS situation in Nigeria in 1991; this was several years after the virus was first detected in the nation (Nigerian Finder, 2017). This rather absence of an efficient proactive foresight at taking on the combat against the disease allowed it to overtake any meaningful effort to be made after then.

HIV/AIDS is endemic in most parts of the world and remains a major cause of morbidity and mortality in Nigeria and Africa at large. Nigeria has the second largest HIV burden in the world. The impact of HIV/AIDS extends beyond those living with the virus. This is because as families struggle with poverty when they lose a bread winner or have the added expenses of caring for economically disabled family members who may die sooner or later, household savings tends to decrease leading ultimately to wider financial depreciation. It also exerts impact on other members of the household (usually wives or children) who may miss school or work in order to take care of the sick person (Cox, 1997). There are many risk factors that contribute to the spread of HIV/AIDS such as commercial sex working, wandering female hawking, itinerant trading, perinatal transmission, unscreened blood transfusion and a host of other deep rooted unhealthy traditional practices. The The World Bank (2016) statistics reveal that HIV prevalence is higher among the female gender than their male counterpart in Nigeria. Mother- to-child transmission (MTCT) or vertical transmission of HIV infection, is the most common medium through which the virus is contracted among this age group as these children are not yet sexually active. Mothers infected with the virus can transmit the virus to their babies in utero, intrapartum or postpartum through breastfeeding.

\subsection{HIV/AIDS and Infant Mortality in Nigeria}

Mothers infected with the virus can transmit the virus to their babies in utero, intrapartum or postpartum through breastfeeding. Shapiro and Lockman (2010) identified three factors that emerged from the HIV epidemic to worsen the ongoing childhood mortality epidemic. First, more than half of HIV infected infants will die within the first two years of life without antiretroviral treatment. This is the major reason that formed the idea of utilizing under-five mortality data. Second, infant feeding options pose a difficult dilemma: longer breastfeeding may increase Mother-To-Child-Transmission (MTCT) of HIV and subsequent HIV-associated mortality, but shorter breastfeeding (or no breastfeeding) may increase mortality from common childhood illnesses. Finally, HIV-exposed but uninfected infants have higher mortality rates than do infants born to HIV-infected mothers even when feeding patterns are similar.

National Agency for the Control of AIDS (2015) remarked that the sites of Prevention-of-Mother-to-ChildTransmission (PMTCT) has increased from 675 in 2010 to 6283 in 2014 while the number of HIV positive pregnant women who received antiretroviral prophylaxis to pregnant mother to child transmission has increased by over 87 percent from 33,891 to 2010 to 63,350 in 2014. Thus, the progress the Nigerian government has made in her response to achieving an end to HIV/AIDS epidemic in the year 2030 was highly commended.

There is a vast number of literature on HIV/AIDS and economic growth in existence. Most of the researches related to the issue at hand are based on just two economic focus. Always, they are either HIV/AIDS or infant mortality and economic growth. On the contrary, this is a three-nexus study that seeks to analyze the simultaneous relationship among HIV/AIDS, infant mortality and economic growth and how they affect one another. Another point worthy of note here is the econometric technique used in the analysis. Vector Error Correction Model (VECM) is more advanced and closer to reality than most of the techniques used in previous studies. The VECM examines a bi-directional causality between variables as variables are considered to be interdependent. This is more realistic and reliable for policy recommendation.

The objective of this study is to assess the relationship among HIV/AIDS, infant mortality and economic growth in Nigeria and specifically, this study seeks to examine the impact of HIV/AIDS on infant mortality and economic growth in Nigeria.

\section{Literature Review}

\subsection{Transmission Mechanism among HIV/AIDS, Infant Mortality and Economic Growth}

The attempt here is to answer the germane question that the study poses. What is the chain of causality among HIV/AIDS, infant mortality and economic growth? A plethora of literature exists with regards to the issue at hand. From previous studies and economic theory, we can contend that both HIV/AIDS and infant mortality rates have serious implications on the economic growth of any nation. In recent times, child mortality is regarded as one 
of the best measures of the health status of a country. In fact, it has been argued that infant/maternal mortality and education indicators such as literacy should be used to indicate a country's developmental status (Hanmer, Lensink, \& White, 2003).

There are various schools of thought with divergent views with respect to the chain of causality between these variables. The first school of thought we consider here are those that tenaciously believe that improvement in human capital (health) leads to economic growth and not the other way around. Ramirez, Ranis, and Stewart (2000) and Grossman (1972) posited that investment in human capital can lay the basis for subsequent growth, that is, investment in education and health can lead to high rates of economic growth as countries which have focused exclusively on economic growth have in the end, achieved neither sustained growth nor human development. This is corroborated by Todaro and Smith (2012) as they claimed both education and health can be seen as vital components of economic growth and development. They further argued that a higher household income is no guarantee of improved health and education, and that human capital must be given direct attention in its own right even in economies that are growing rapidly. This is because improved health and education help families escape from the vicious circles of poverty in which they are trapped. This has been foreseen by the British economist, Dudley Seers in 1969 who pioneered the 'Dethronement of GNP'. In his postulation, he reasoned that if the central problems of poverty, inequality and unemployment grow worse in an economy, it cannot be said that such economy has experienced economic development even if per capita income has soared.

The second school of thought belongs to the group that steadfastly cling to the ideology that changes in health are attributed to changes in income. Ravallion (1997) admits that sustained improvements in welfare are best brought about by increasing income. Upadhyay and Srivastava (2015) supported this by asserting that in countries with low per head GDP, macroeconomic growth will increase the average income of individuals and improve the incomes of poor people which will in turn improve the quality of life by providing better consumption of goods, increased access to healthcare services, better housing and sanitation and reduced rates of infant mortality. There is a third school that does not fall into any of the above categories. Countries in Africa and particularly Nigeria have exhibited unconventional patterns in their infant mortality rates as these rates continue to consistently decline despite fluctuations in real GDP. This can be attributed to other factors other than economic growth such as medical advances and improved technology. Vaccinations and immunization has played a vital role in the eradication and decline of the incidence of small pox, chicken pox, measles, polio, meningitis and so on which speeds up mortality improvement. Hanmer et al. (2003) in their analysis confirmed that there is a strong but imperfect link between income and infant mortality.

\subsection{Transmission Mechanism from HIV/AIDS to Economic Growth}

Specifically, HIV/AIDS has created severe economic impacts in many countries especially Nigeria because it strikes people in the most productive age group. There are two channels through which HIV/AIDS affect economic growth; reduction in labour participation and reduction in capital accumulation.

\subsubsection{Channel 1: Lower Economic Growth through Reduction in Capital Accumulation.}

AIDS $\rightarrow$ Treatment $\rightarrow$ Decrease in Savings $\rightarrow$ Lower Capital Accumulation $\rightarrow$ Lower Economic Growth

From the above, the AIDS epidemic on a macro level will divert public spending from investments in physical and human capital to health expenditures in the form of treatment costs which leads to a decrease in savings, lower accumulation of capital and slower growth of the GDP (Manuelli \& Yurdagul, 2016). Foreign and domestic private investments may also decline if potential investors become convinced that the epidemic is seriously undermining the rate of returns to investment which encourages capital flight.

\subsubsection{Channel 2: Slow Economic Growth Due to Reduction in Labour Participation}

AIDS $\rightarrow$ Invalidity $\rightarrow$ Reduction in Labour Participation $\rightarrow$ Reduction in Economic Growth

It a known fact that HIV/AIDS targets the young and vibrant youths at their most productive age and these young individuals constitute a large portion of the labour force. When a considerable number of individuals in this age group are infected with the virus, they become invalids as they can no longer work efficiently. This tends to slow down or reverse growth in the labour supply, productivity and economic growth (Iya, Purokayo, \& Gabdo, 2012; Kithinji, 2015). However, it has been argued that economic impact can vary with regards to the sector involved. That is, the effect depends on whether or not the virus affects hard-to-replace skilled labour and also whether or not there is a substantial pool of surplus labour to replace those lost (Levinsoln, Shisana, McLaren, \& Zuma, 2013).

Based on the above, regardless of the channel or means of transmission, it could be concluded that HIV/AIDS has a detrimental effect on any economy irrespective of whether or not there is a substantial pool of labour to replace those losses. If replacement is possible, there is the cost of training new workers to replace skilled and experienced individuals and if replacement is not possible, it becomes worse.

\subsection{Transmission Mechanism from Economic Growth to HIV/AIDS}

The World Bank (1997) opines that widespread poverty and unequal distribution of income that typify underdevelopment appear to stimulate the spread of HIV. The channel through which slow economic growth feeds HIV/AIDS is poverty. International Labour Office (ILO) (2005) reports that there are strong bi-directional linkages between HIV/AIDS and poverty in resource poor settings. In fact, HIV/AIDS is both a manifestation of poverty conditions that exist, taking hold where livelihoods are unsustainable.

\subsubsection{HIV/AIDS $\leftrightarrow$ Poverty}

Poverty can make one engage in risky sexual/social behaviour as well as limit access to healthcare, HIV testing and medications. Consider the vicious circle below that links the variables of interest. 


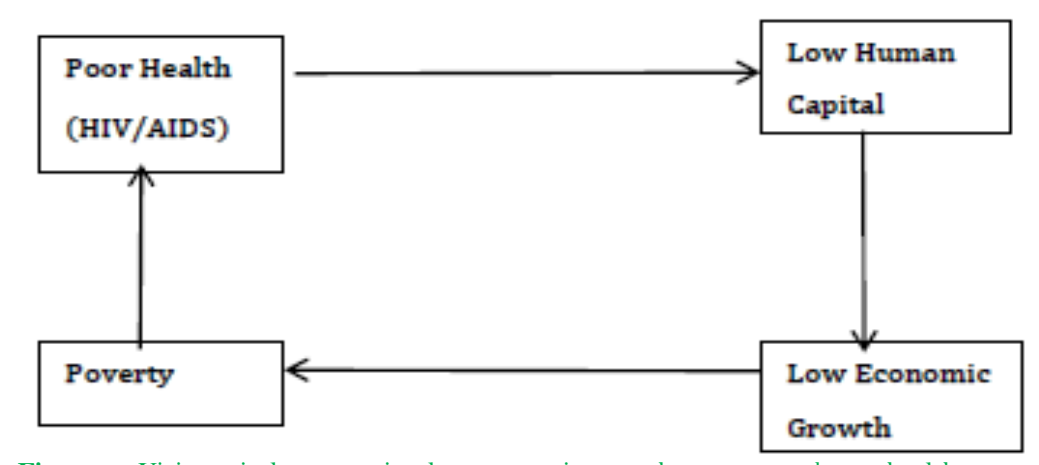

Figure-1. Vicious circle connecting low economic growth, poverty and poor health.

Figure 1 demonstrates the connection between low economic growth, poverty, poor health and low human capital. Low economic growth creates poverty which generates risky health habit, which in turn slows human capital formation which results in low economic growth. This circle continues until there is a strategic policy shift to advance a different economic growth and development trajectory.

\subsection{Transmission Mechanism from HIV/AIDS to Infant Mortality}

Most children acquire the virus through transmission from HIV-infected mothers, therefore. The incidence of paediatric HIV reflects that of HIV infection in women of child- bearing age. MTCT of HIV which can occur during pregnancy, delivery or breastfeeding is responsible for more than $90 \%$ of HIV infection in children worldwide (UNAIDS/WHO, 1998).

\subsubsection{HIV/AIDS $\rightarrow$ MTCT $\rightarrow$ Infant Mortality}

Given the dilemma of infant feeding options, there is very little information on the safety of infant-feeding alternatives for sero-positive mothers. These alternatives include commercial infant formula, home-made infant formula, heat-treated expressed breast milk and wet-nursing. Worthy of attention are identification of approaches to treating expressed breast milk to eliminate the risk of transmission while preserving the milk's nutritional content (WHO, 2005) and inculcation of unseen values of human and emotional instinct development in the infant. From the above, we can comfortably reason that there is a uni-directional chain of causality between HIV/AIDS and infant mortality.

\subsection{Empirical Literature}

Waziri, Nor, Abdullah, and Adamu (2016) assessed the effect of the prevalence of HIV/AIDS and life expectancy on the economic growth of 33 SSA countries over the period of 11 years (2002- 2012). The study employed a dynamic panel approach as opposed to the static traditional approach utilized in literature. They used the differenced GMM, as proposed by Arellano and Bond (1991). The result revealed that HIV/AIDS is statistically significant and negatively related to growth which is consistent to economic theory and apriori expectation.

McDonald and Roberts (2006) employed an augmented Solow model, a human capital approach to estimate the elasticity of AIDS in relation to economic growth. The study utilized the econometric approach of OLS and instrumental variables estimation using time series data for 112 countries over the period 1960 to 1998 . The result revealed that the macroeconomic effects of the HIV/AIDS epidemic have been substantial especially on the per capita income of Africans while the human and social costs ofthe epidemic are a major cause for concern.

Delacruz (2007) using the OLS and 2SLS carried out an estimation on the impact of HIV/AIDS on economic growth from 1990-2004 across 86 industrial and developing countries. He created 3 simultaneous equations where explanatory variables are entered both independently and linearly. Contrary to expectations, the result obtained were mixed as some countries such as Botswana, Lesotho, Uganda, and Rwanda exhibit high growth rates parallel to high HIV prevalence while on the other hand, we also discover low HIV prevalence related to low income countries such as Brazil, Mexico, Philippines, Germany, Sweden and Finland.

Maijama'a and Mohammed (2013) examined the impact of HIV/AIDS on economic growth and development in Nigeria using the cointegration and error correction technique and discovered that HIV/AIDS has a negative impact on real GDP in Nigeria. They used primary data, a total of 360 respondents comprising 180 persons infected with HIV/AIDS and 180 uninfected persons were selected using stratified sampling technique.

Bloom and Mahal (1997) conducted a cross country analysis that examines the statistical link between HIV prevalence rate and the growth rate of per capita GDP across 51 developing and industrial countries from 19801992. They used the 2SLS to estimate their parameters and discovered that HIV prevalence is higher in countries with slower GDP growth. They however concluded that the AIDS epidemic may have serious implications for economic development. Masha (2004) examined the macroeconomic impact of prevention and increased access to healthcare in Botswana from 2005-2015 and realized that for a country in which natural resource extraction constitute a large share of GDP, it is very important to account for the sector separately because they are very likely to be prone to exogenous shocks such as international changes in the price of natural resource. Crampin et al. (2003) in Mahy (2003) used data from a longitudinal study site in Malawi to measure child mortality to HIV positive women versus HIV negative women. They found significantly different under-five mortality levels for HIV-positive mothers (46 percent) versus HIV-negative mothers (16 percent). Whether this increased mortality is due to vertical transmission or the negative impacts of an ill-parent are not established. However, this is a clear evidence for a correlation between mother and child mortality in high HIV-prevalence settings.

A vast number of the literatures reviewed above have drawn our attention to some obvious flaws which create a gap that this study aims to fill as an improvement. Majority of the researchers based their study on just one variable (HIV/AIDS) linked to economic growth. However, it has been proven that HIV/AIDS has great implications on other health variables (such as infant mortality, under-5 mortality, maternal mortality and others) 
and these variables in turn affects economic growth. This is the reason why this study links three variables and examines the relationship among them. Furthermore, some of these studies were carried out far back in time and since then, a lot of plans and policies have been adopted and the effects of these changes on the economy were not considered. In the same vein, flaws can be found in the method of estimation. Although the OLS technique possesses the desirable BLUE (Best, Linear and Unbiased Estimates) properties, and cointegration examines the existence of a long run relationship between variables, these techniques assume the presence of a uni-directional chain of causality between variables. As an improvement on this, this study adopted the Vector Error Correction Model (VECM) which is closer to reality as variables are considered to be interdependent. Finally, this research is country specific as our study is confined to the Nigerian economy. This is justified because as of today, she has the second highest number of persons living with HIV/AIDS in the world. After conducting series of empirical analyses using real life data, the study intends to prescribe recommendations that if taken, will not only halt the spread of the virus, reduce infant mortality but also would yield the most coveted phenomenon of sustainable economic growth and development in Nigeria.

\section{Theoretical Framework, Methodology and Model Specification}

\subsection{Theoretical Framework}

This chapter presents the theoretical framework and empirical model used to achieve this study's objectives. The study adopts an econometric model to find out the relationship among HIV/AIDS, infant mortality and economic growth in Nigeria. The theoretical foundation hinges on the Grossman model.

The Grossman Model by Grossman (1972) was the first to construct a theoretical model of the demand for health capital. He proposed a model of health production inspired by the human capital model of Becker (1967). Grossman described the demand for health and health care via the theory of human capital. Healthy workers are more physically and mentally fit and they take less time off work due to illness and are more productive. Health is therefore viewed as a durable capital stock that generates production benefits. The model is concerned with how individuals allocate their resources to produce health. This model goes beyond traditional demand analysis as it utilizes the idea that the individual is a producer of health.

\subsubsection{The Grossman Model}

Consider an individual with a planning horizon of two time periods. During each period he or she experiences a nonnegative amount of sick time $t^{\mathrm{s}}$, which is lower than the larger health stock $H$. In other words, healthy time constitutes the non-tradable return of the unobserved stock of health. The individual derives positive utility from consumption goods $X$ while deriving disutility from sick time $t(H)$. The marginal rate of substitution between sick time and consumption does not change with aging. Future utility is discounted by a subjective factor $\beta \leq 1$. Thus, the individual maximizes discounted utility denoted by $U$ in Equation 1.

$$
\begin{gathered}
U=U\left(t^{2}\left(H_{o}\right), X_{o}\right)+\beta U\left(t^{s}\left(H_{i}\right), X_{l}\right) \\
\frac{\partial U}{\partial t^{s}} \prec 0, \frac{\partial^{2} U}{\partial\left(t^{s}\right)^{2}} \succ 0, \frac{\partial U}{\partial X}>0, \frac{\partial^{2} U}{\partial X^{2}}<0, \frac{\partial t^{s}}{\partial H}<0
\end{gathered}
$$

The crucial component of the Grossman model is the equation that defines the change in the health stock over time. On the one hand, health capital depreciates at a rate $\delta$, causing health to worsen over time and $\delta$ is not constant. On the other hand, the individual can increase health capital by investing I. This may either be in the form of purchase of medical services $\mathrm{M}$ or spending tI units of time on preventive effort (such as balanced diet, exercise, abstinence from cigarettes and other harmful substances). In all, one has

$$
H 1=H O(1-\delta)+I\left(M O, t^{t}\right)
$$

$$
\frac{\partial I}{\partial t^{I}}>0, \frac{\partial^{2} I}{\partial\left(t^{I}\right)^{2}} \prec 0
$$

It is pertinent to note here that Equation 2 constitutes a constraint that we can use to solve the maximization problem using the lagrange multiplier.

\subsection{Methodology and Model Specification}

In view the objective of this study, the empirical methodology employs several econometric procedures within a multiple linear regression framework. In order to avoid spurious regression results, the econometric procedure of this study entails pre-estimation diagnostic analysis, long-run and short-run analysis. First, the pre-estimation diagnostic analysis involvesthe Augmented Dickey-Fuller (ADF) tests of unit roots or non-stationarity. EngleGranger two stage and the Philip-Ouliariscointegration tests is used to examine the long run relationship amongst the variables of interest. The error correction mechanism model is used to capture effects of the specified regressors in the model on economic growth and also to determine the amount of deviations from its long-run equilibrium.

The empirical growth regression model is estimated using time series data set spanning a 36-year period (1980-2015). Data on economic growth and health indicators are sourced from the Central Bank of Nigeria (2014) World Bank Development Indicators and the National Bureau of Statistics. The study aims to investigate the interacting and transmission causalities between HIV/AIDS, infant mortality and economic growth and their resultant equilibrium convergence in the long run. Within the framework, the short run divergences and speed of adjustments amongst the incorporated variables will be analysed. The econometric technique Vector Autoregression(VAR) was pioneered by Sims (1980) and its provides a flexible and traceable estimation technique for analysing time series. The technique is superior since it does not dichotomize economic variables into endogenous and exogenous, rather treating all variables in the simultaneous systems equations as endogenously determined within the estimated model Arodoye (2012). However, where the variables are found to be cointegrated, the VAR becomes unsuitable and this justifies the use of the Vector Error Correction Model (VECM). 
Based on Grossman (1972) investment model, the price of health depends on many other variables besides the price of medical care. It is from this assumption we deduce our empirical model.

$$
\text { LHIVPR }=f(\text { LRGDP, LU5M, LGHEXP, LLITR, LPCI) }
$$

Equation 3 indicates that LHIVPR is a function of LRGDP, LU5M, LGHEXP, LLITR, and LPCI

The Vector Error Correction Model (VECM) form of Equation 3 is specified as:

$$
\Delta \ln Z_{t}=\beta_{0}+\sum_{i=1}^{n} \beta_{1} \Delta \ln Z_{t-1}+\phi E C M_{t}+\mu_{i t}
$$

Equation 4 is the specification of the over-parameterized system VECM which shows that the vector of variables is dependent on the vector of lagged variables.

Where:

$Z_{\mathrm{t}}=\mathrm{f}($ LHIVPR, LRGDP, LU5M, LGHEXP).

$Z_{\mathrm{t}-1}=\mathrm{f}$ (LHIVPRt-1, LRGDPt-1, LU5Mt-1, LGHEXPt-1).

$Z_{t}=$ Vector of variables.

$\mathrm{Z}_{\mathrm{t}-1}=$ Vector of lagged variables

$\mathrm{ECM}_{\mathrm{t}}=$ Error correction term.

$\mu_{\mathrm{it}}=$ Stochastic error term.

$\beta_{0}=$ Vector of intercept terms.

Hence, the explicit specification of the over-parameterized system VECM can be written as;

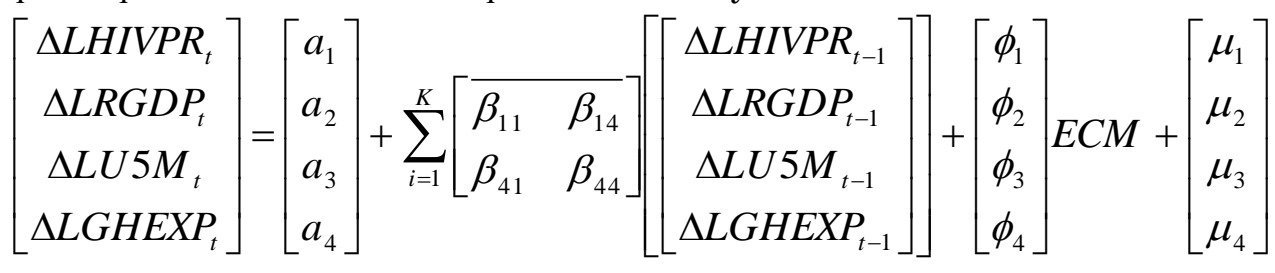

\begin{tabular}{|c|c|c|}
\hline \multicolumn{2}{|c|}{ LHIVPR $=$ Natural log of HIV prevalence rate } & $\Phi=$ error correction coefficient \\
\hline \multicolumn{2}{|c|}{ LRGDP $=$ Natural log of real GDP as a proxy for } & $\beta=$ coefficients of the vector matrix variables \\
\hline \multicolumn{3}{|c|}{ economic growth } \\
\hline \multicolumn{2}{|c|}{ LU5M $=$ Natural $\log$ of under -5 mortality } & $\mu=$ stochastic error term \\
\hline LGHEXP $=$ & $\begin{array}{l}\text { Naturallog of government health } \\
\text { expenditure }\end{array}$ & $\Delta=$ first order difference operator \\
\hline
\end{tabular}

Where:

Table-1. Regression Variables Description

Table 1 above describes the regression variables used in our Vector Error Correction Model specified in Equation 4 .

\section{Presentation and Analysis of Empirical Results}

This section presents and analyses the empirical results of the data sourced for this study. Among such results are; unit root tests, cointegration, granger causality tests, Vector Error Correction Mechanism (VECM), variance decomposition and others. The variables were estimated using data in their natural log form so that their coefficients represent elasticities.

\subsection{Unit Root Test Result}

Econometric studies have shown that most macroeconomic time series variables are non-stationary and nonstationary variables leads to spurious results that would make estimates biased and inconsistent (Engle \& Granger, 1987). To avoid producing spurious results that would make parameter estimates inconsistent and biased, all the variables utilized for this study were tested to ascertain the stationarity status. The Augmented Dickey Fuller (ADF) approach was used to conduct this test. The result is shown below:

Table-2.Unit root test results.

\begin{tabular}{c|c|c|c|c|c|c}
\hline & \multicolumn{2}{|c|}{ Unit Root Test at Levels I(0) } & \multicolumn{2}{c}{ Unit Root test at First Difference I(1) } \\
\hline Variable & $\begin{array}{c}\text { ADF test } \\
\text { statistic }\end{array}$ & $\begin{array}{c}\text { ADF critical } \\
\text { value at 5\% }\end{array}$ & Remark & $\begin{array}{c}\text { ADF test } \\
\text { statistic }\end{array}$ & $\begin{array}{c}\text { ADF critical } \\
\text { value at 5\% }\end{array}$ & $\begin{array}{c}\text { Remark } \\
\text { valuen }\end{array}$ \\
\hline LHIVPR & -5.637036 & -4.374307 & Stationary & -7.705222 & -3.622033 & Stationary \\
\hline LGHEXP & -2.052466 & -3.544284 & Non-stationary & -4.561836 & -3.55759 & Stationary \\
\hline LU5M & -5.994276 & -3.580623 & Stationary & -5.994276 & -3.580623 & Stationary \\
\hline LRGDP & -2.321868 & -3.544284 & Non-stationary & -6.299132 & -3.548490 & Stationary \\
\hline
\end{tabular}

The results that appear in Table 2 above show that apart from LHIVPR and LU5M, all others variables were not stationary at levels, but after first difference, all variables were found to be stationary at the $5 \%$ level of significance.

\subsection{Cointegration Test}

After stationarity has been established, the study further tested for cointegration. This test is conducted to determine if there is a convergence between the long run equilibrium and the short run dynamics of the time series data. This therefore estimates a long run relationship between economic variables. This is very important for the purpose of policy making. Since the study involves a system of equations, it therefore follows the Johansen and Juselius (1990) approach. Thus, the maximum eigenvalue and trace tests were utilized in determining the number of cointegrating vectors. The cointegration test results are presented below: 
Table-3. Cointegration test results.

\begin{tabular}{c|c|c|c|c|c}
\hline & & \multicolumn{2}{|c|}{ Trace Test } & \multicolumn{2}{c}{ Max- Eigen Test } \\
\hline $\begin{array}{c}\text { Hypothesized } \\
\text { No. ofCE (s) }\end{array}$ & Eigenvalue & Trace Statistic & $\begin{array}{c}\text { 0.05 Critical } \\
\text { Value }\end{array}$ & $\begin{array}{c}\text { Max-Eigen } \\
\text { Statistic }\end{array}$ & $\begin{array}{c}\text { o.05Critical } \\
\text { Value }\end{array}$ \\
\hline None ** & 0.958629 & 180.1317 & 95.75366 & 76.44448 & 40.07757 \\
\hline At most 1 ** & 0.873551 & 103.6873 & 69.81889 & 49.63003 & 33.87687 \\
\hline At most 2 & 0.645675 & 54.05723 & 47.85613 & 24.90100 & 27.58434 \\
\hline At most 3 & 0.482702 & 29.15624 & 29.79707 & 15.81928 & 21.13162 \\
\hline At most 4 & 0.349585 & 13.33696 & 15.49471 & 10.32348 & 14.26460 \\
\hline At most 5 & 0.117999 & 3.013477 & 3.841466 & 3.013477 & 3.841466 \\
\hline Note Tran
\end{tabular}

Note: Trace test indicates 3 cointegrating eqn(s) at the 0.05 level.

Max-eigenvalue test indicates 2 cointegrating eqn(s) at the 0.05 level.

*** denotes rejection of the hypothesis at the 0.05 level.

From Table 3 above, the test statistic of trace and maximum-eigen values reveals the existence of 3 and 2 cointegrating equations at the $5 \%$ level respectively. Therefore, the study rejects the null hypothesis of no cointegration among the variables at the $5 \%$ level. This endorses the existence of a long run relationship among the variables of interest.

\subsection{Optimum Lag Length Selection}

To estimate Vector error correction model, the first step is to establish the optimum lag length. This was determined using the Akaike Information Criterion(AIC) among others as shown on Table 4. The decision was based on the result from AIC which implies that the optimal lag length of this study is 2 . The result is presented below:

Table-4. Optimal lag length

\begin{tabular}{c|c|c|c|c|c|c}
\hline Lag & LogL & LR & FPE & AIC & SIC & HQ \\
\hline 0 & -7.262725 & NA & $3.00 \mathrm{e}-05$ & 0.938560 & 1.134903 & 0.990650 \\
\hline 1 & 175.4476 & 289.2914 & $2.85 \mathrm{e}-11$ & -12.95397 & -11.97226 & -12.69352 \\
\hline 2 & 221.6815 & $57.79230^{*}$ & $2.61 \mathrm{e}-12^{*}$ & $-15.47346^{*}$ & $-13.70638^{*}$ & $-15.00465^{*}$ \\
\hline
\end{tabular}

\subsection{Error Correction Estimates}

The ECM corrects for disequilibrium, it indicates the speed of convergence back to equilibrium in the event of any temporary disturbance in the economy. Economic theory requires that the coefficients should be negatively signed, statistically significant and their absolute values should be between $\mathrm{O}$ and unity.

Table-5. Error correction estimates.

\begin{tabular}{c|c|c|c|c}
\hline Error Correction & D(LHIVPR) & D(LRGDP & D(LU5M) & D(LGHEXP) \\
\hline ECM & -0.068459 & -0.692457 & -0.602283 & -0.533262 \\
\hline & {$[-1.92049]$} & {$[-2.71209]$} & {$[-2.61462]$} & {$[-4.63319]$} \\
\hline
\end{tabular}

\begin{tabular}{|c|c|c|c|c|}
\hline Explanatory Variables & D(LHIVPR) & D(LRGDP) & D(LU5M) & D(LGHEXP) \\
\hline \multirow[t]{2}{*}{$\mathrm{D}(\mathrm{LHIVPR}(-1))$} & -0.208212 & -1.974125 & 0.025950 & -34.49622 \\
\hline & {$[-0.72129]$} & {$[-0.49719]$} & {$[1.35766]$} & {$[-2.71425]^{* *}$} \\
\hline \multirow[t]{2}{*}{ D(LHIVPR(-2)) } & 0.104565 & 6.995306 & -0.005865 & -24.94461 \\
\hline & {$[0.33791]$} & {$[1.64344]^{*}$} & {$[-0.28622]$} & {$[-1.83087]^{*}$} \\
\hline \multirow[t]{2}{*}{$\mathrm{D}(\operatorname{LRGDP}(-1))$} & 0.036575 & 0.647023 & 0.000103 & 2.723364 \\
\hline & {$[1.41458]$} & {$[1.81930]^{*}$} & {$[0.06011]$} & {$[2.39234]^{* *}$} \\
\hline \multirow[t]{2}{*}{$\mathrm{D}(\operatorname{LRGDP}(-2))$} & 0.001997 & 0.384652 & -0.001386 & 2.745666 \\
\hline & {$[0.07009]$} & {$[0.98172]$} & {$[-0.73510]$} & {$[2.18927]^{* *}$} \\
\hline \multirow[t]{2}{*}{$\mathrm{D}(\mathrm{LU} 5 \mathrm{M}(-1))$} & 1.632488 & -243.1318 & 1.241893 & -216.0696 \\
\hline & {$[0.24988]$} & {$[-2.70559]^{* *}$} & {$[2.87092]^{* *}$} & {$[-0.75118]$} \\
\hline \multirow[t]{2}{*}{$\mathrm{D}(\mathrm{LU} 5 \mathrm{M}(-2))$} & 1.724000 & 150.0219 & -0.486131 & 452.5738 \\
\hline & {$[0.30779]$} & {$[1.94721]^{*}$} & {$[-1.31077]$} & {$[1.83518]^{*}$} \\
\hline \multirow[t]{2}{*}{$\mathrm{D}(\operatorname{LGHEXP}(-1))$} & 0.009971 & 0.168062 & 0.000215 & -0.33472 \\
\hline & {$[1.85765]^{*}$} & {$[2.27632]^{* *}$} & {$[0.60513]$} & {$[-1.41638]$} \\
\hline \multirow[t]{2}{*}{$\mathrm{D}(\mathrm{LGHEXP}(-2))$} & 0.002338 & 0.104088 & 0.000128 & 0.046509 \\
\hline & {$[0.41054]$} & {$[1.32891]$} & {$[0.34013]$} & {$[0.18551]$} \\
\hline \multirow[t]{3}{*}{ ECM } & -0.068459 & -2.092457 & -0.002283 & -4.033262 \\
\hline & {$[-1.22049]$} & {$[-2.71209]^{* *}$} & {$[-0.61462]$} & {$[-1.63319]^{*}$} \\
\hline & \multicolumn{3}{|c|}{ Summary Statistics } & \\
\hline R-squared & 0.964970 & 0.647196 & 0.995734 & 0.606185 \\
\hline Adj. R-squared & 0.940719 & 0.402947 & 0.992781 & 0.333545 \\
\hline S.E. equation & 0.014640 & 0.201366 & 0.000969 & 0.644546 \\
\hline F-statistic & 39.79063 & 2.649738 & 337.1731 & 2.223385 \\
\hline Akaike AIC & -5.311164 & -0.068365 & -10.74092 & 2.258479 \\
\hline Schwarz SC & -4.817471 & 0.425328 & -10.24723 & 2.752172 \\
\hline Mean dependent & 0.021285 & 0.121669 & -0.028942 & 0.193311 \\
\hline S.D. dependent & 0.060127 & 0.260603 & 0.011409 & 0.789529 \\
\hline
\end{tabular}

Note: Standard errors in ( ) \& t-statistics in []

t-values significant $*$ and $* *$ significant at $10 \%$ and $5 \%$ levels respectively. 
Table 5 shows that the four cointegrating equations are adjusting. All the coefficients meet the economic requirements. Aside LHIVPR whose speed of adjustment is only $6.8 \%$, other variables have relatively high speed of adjustment at $69.2 \%, 60.2 \%$ and $53.3 \%$ which again confirms the stability of the economy. The t-values of all the variables were found to be significant at the $5 \%$ level.

Table 6 presents the VECM estimates of our regression model with four distinct equations. However, to make an incisive study, we will focus our analysis exclusively on equations 1, 2 and 3 as these equations will enable us achieve the objectives of this study.

\subsubsection{Equation One Analysis}

In this equation, HIV prevalence is the dependent variable while all other variables are the explanatory variables. The coefficient of the intercept although not statistically significant implies that there would still be HIV prevalence rate of about $10.6 \%$ in the economy even if the coefficient of all the explanatory variables are assumed to be zero. In the first lag, the coefficient of LHIVPR, -0.208 implies that $1 \%$ increase in LHIVPR in the immediate past year will result in $20.8 \%$ decline in the current LHIVPR. This can be attributed to the effectiveness of the antiretroviral therapy (ART) as treatment in the past year reduces the spread of the virus in the current year. In the second lag, a slight change is recorded as LHIVPR has an inverse impact on current LHIVPR. A percentage increase in two lagged periods of LHIVPR will result in a 10.5\% increase in current LHIVPR. This is a proof of the devastating and self- feeding effect of the virus. However, the variable is not statistically significant even at the moderate rate of $10 \%$ level.

Economic growth has a positive relationship with LHIVPR in both lags as a percentage increase in LRGDP either period will lead to a $3.65 \%$ or $0.19 \%$ increase current LHIVPR respectively. In other words, as income rises, HIV prevalence rate also rises. This confirms (Gillespie, Kadiyala, \& Greener, 2008) whose study asserts that HIV is more prevalent among richer and more educated individuals because they have higher rate of partner change and also serial autonomy and spatial mobility.

Under-5 mortality was found to be strongly and positively related with LHIVPR in both lags. A one percent increase in either lag will yield a $63.2 \%$ or $72.49 \%$ respectively in the HIVprevalence rate of the present period. This is suggestive of the prevalence rate of the virus among parents as the infants are not yet sexually active. Although this conforms to economic theory, the variables are not significant at $5 \%$.

Government health expenditure was found surprisingly to be positively correlated with HIV prevalence rate in both lags. A one percent increase in either lag will result in a $0.99 \%$ or $0.23 \%$ rise in LHIVPR respectively. Though this is opposing to both apriori expectations and theoretical expectations, this can be attributed to corruption and inefficiency in the sector. The allocation given to the health sector is usually not sufficient and the little they have is being diverted to private pockets. The variable was only found to be statistically significant in the first lag at the $10 \%$ level. The $\mathrm{R}^{2}$ of $96 \%$ and its adjusted counterpart of $94 \%$ implies that about $94 \%$ of the systematic variations in the current HIV prevalence rate are accounted for by its past values and that of LRGDP, LU5M and LGHEXP. The F-statistic of $39 \%$ confirms the overall significance of the model and it is significant at the $1 \%$ level.

\subsubsection{Equation Two Analysis}

This equation regards economic growth (LRGDP) as the dependent variable and the impact of all other variables on the dependent variable are analysed. The intercept is statistically significant and it implies that if all other variables are assumed to be zero, there would be not be economic growth. LHIVPR recorded mixed results as it conformed to economic theory only in the first lag. A percentage increase in last year's HIV prevalence rate yields a decrease of about $197.4 \%$ in this year's economic growth. This can either be through reduction in labour participation or reduction in capital accumulation which results in a decline in economic growth. Though the coefficient was correctly signed, it was not statistically significant. However, in the second lag, the coefficient was not correctly signed but was significant at the $10 \%$ level.

Economic growth was found to be positively correlated with itself in both lags. This conforms to apriori expectations as a percentage increase of economic growth in either lag will result in a rise of $64.7 \%$ or $38.4 \%$ respectively in the current real GDP. This shows that the economy is self-driven. The coefficients are correctly signed but only the t-value of the first lag passed the test of significance at the $10 \%$ level.

The LU5M variable was correctly signed in lag 1 with a coefficient of (-243.13) and significant even at the stringent level of $1 \%$. Under-5 mortality was found to have a very strong but negative impact on economic growth which conforms to economic theory and apriori expectations. However, in lag 2 , the coefficient of 150.02 implies the presence of a very strong but positive relationship of LU5M with economic growth. The coefficient was significant at the $5 \%$ level.

LGHEXP was correctly signed in both lags and found to have a positive impact on economic growth. A percentage rise of LGHEXP in either lags will yield a $16.8 \%$ or $10.4 \%$ increase in current economic growth. This affirms the assertions of the school of thought that tenaciously believe that investment in human capital leads to economic growth.

The $\mathrm{R}^{2}$ implies that about $64 \%$ of the systematic variations in economic growth are accounted for by the independent variables. After adjusting for degrees of freedom, the coefficient was reduced to $40 \%$. The F- statistic value is found to be significant at the moderate rate of $10 \%$.

\subsubsection{Equation Three Analysis}

In this equation, under-5 mortality is the dependent variable and the impact of all other variables on it are analysed. The coefficient of the intercept implies that there would still be under-5 mortality rate of about $0.22 \%$ even if all the explanatory variables are zero. Conforming to economic theory, LHIVPR in lag 1 has a positive correlation with LU5M as a one percent increase in LHIVPR in the immediate past year leads to a $2.6 \%$ increase in LU5M presently. This is corroborated by the fact that children die from either the HIV virus itself before the age of 2 , or because of lack of maternal care if their mothers are either dead or incapacitated as a result of the virus. In the second lag however, we record a negative relationship as increase in HIVPR of two period lag will result in a 
$0.58 \%$ decline in the current U5M rate. This is an affirmation of the effectiveness of the ART and other preventive mechanisms in curbing the MTCT of the virus. The small magnitude of the coefficient points out that there is still room for improvement. The t-values were not statistically significant at the $5 \%$ level.

The coefficient of LRGDP in the first lag indicates that a one percent increase in LRGDP will result in only about $0.01 \%$ increase in LU5M. Although the coefficient is not correctly signed, its magnitude is very small and it is not statistically significant at the $5 \%$ level. But in the second lag, a percentage increase in economic growth leads to a $0.14 \%$ decline in LU5M. This implies that the plans and policies adopted to halt U5M are effective but at a very slow pace. The coefficient was not also significant at the $5 \%$ level.

LU5M is positively correlated with itself in the first lag with a coefficient of 1.2418 . this is a clear pointer to the fact that LU5M is self-driven and self-feeding. This implies that a percentage increase in last year's U5M will yield approximately a $124.1 \%$ increase in current U5M. However, in the second lag, the coefficient of -0.486 implies that a one percent increase in two period lagged value of LU5M will yield a $48.6 \%$ decline in current LU5M. A reasonable explanation for this is that as with all other health variables, the dividend of investment in LU5M is not reaped immediately.

The $\mathrm{R}^{2}$ and its adjusted counterpart indicate that about $99.2 \%$ of the variations in LU5M can be attributed to changes in the explanatory variables. The F- statistic of 337.17 confirms the overall significance of the model.

\subsection{Impulse Response Functions (IRFs) Estimates}

The Impulse Response Functions describes the response of one variable to a one-unit impulse in the specified value of the variable with all other variables at time $t$ (Hamilton, 1994). The IRFs analyzes the path followed by the variables to return to equilibrium identifying each innovation in a particular variable in the matrix vector, the effect of a one-unit shock on the entire vector system. The IRF graph shows the movement in the individual variables taking into account the identified shocks in the variable of interest per time.
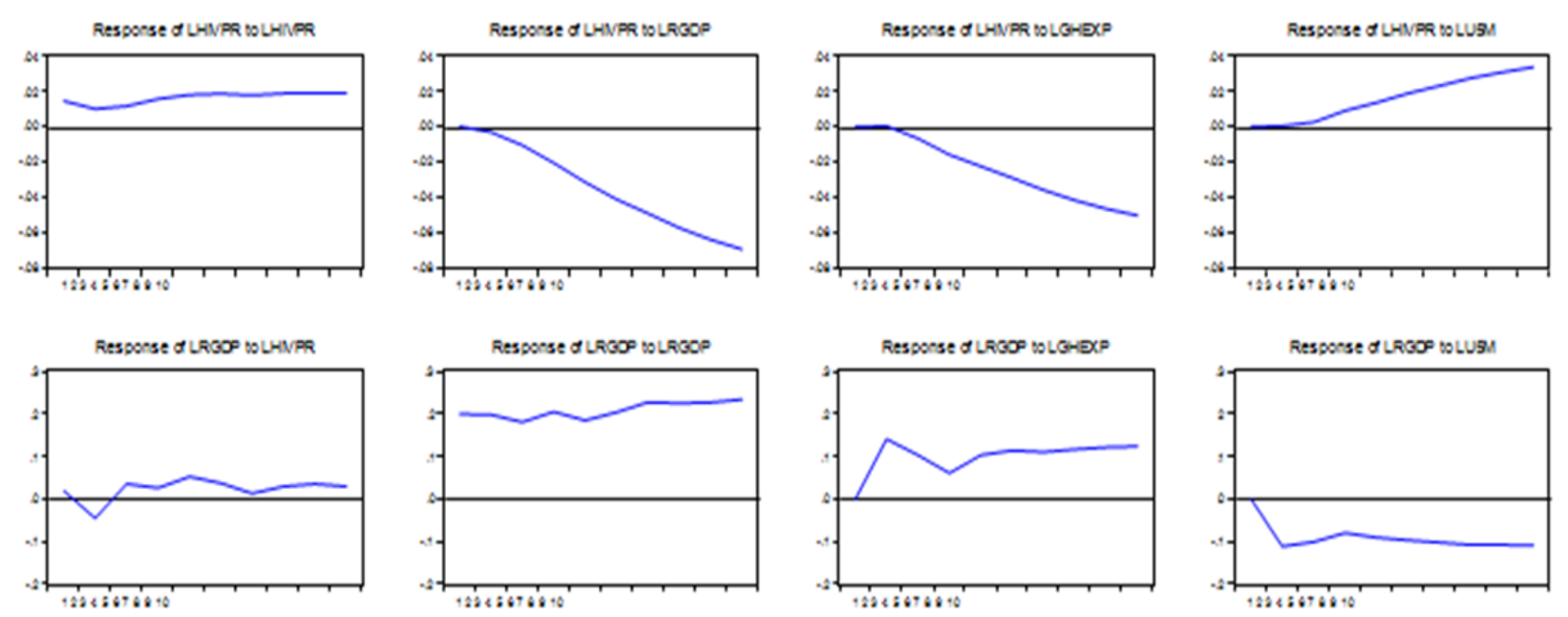

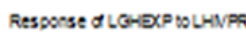

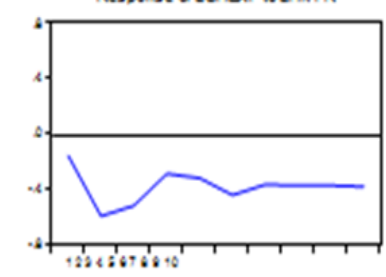

Ressorse đLOHDP toLACOP

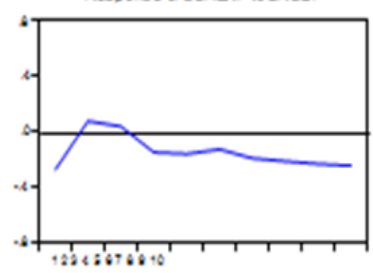

Fessorse dLOMDP WLLORE

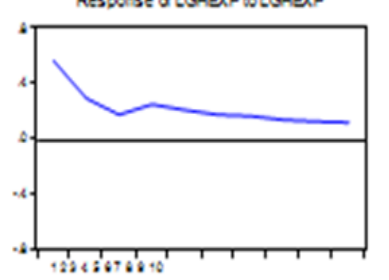

Fesporse d L Lexp toLUg:

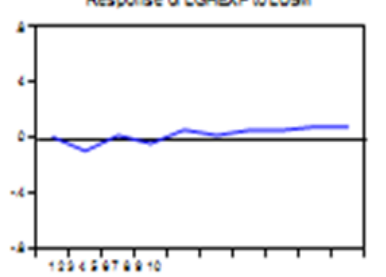

Resporse \& LU9M D LRCOR
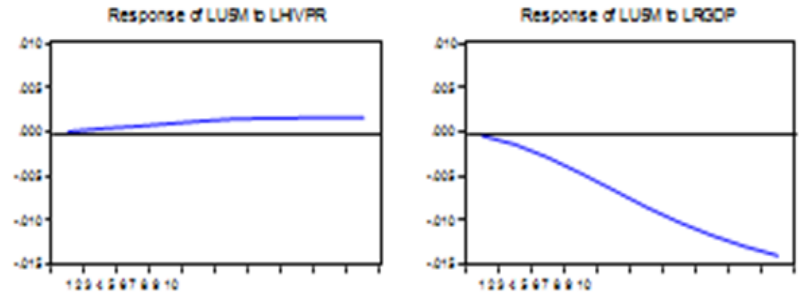

Fesporse d LUSM D LGDP

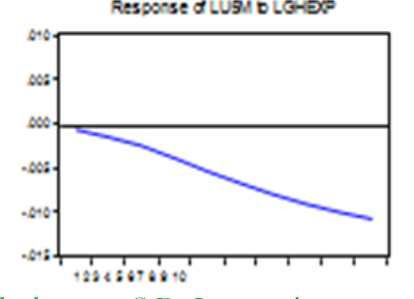

Fesporse \& LUMU D LISM

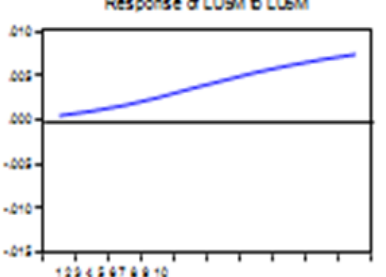

Figure-2. Response to Cholesky, one S.D. Innovations.

Figure 2 presents the impulse response function for LHIVPR, LRGDP, LGHEXP and LU5M against each of their own shocks and against the shocks of other variables in the regression model.

The graph shows the impulse response function for LHIVPR against its own shocks and innovations in economic growth, government health expenditure and under-5 mortality over a ten-year period. The result reveals that HIV prevalence rate shocks on itself have a positive correlation from the beginning of the time horizon till the end of the period. The response of LHIVPR to economic growth showed that the relationship was consistently negative from the first period to the tenth. When the impulse is LGHEXP, the response of LHIVPR was zero for the first two periods and became consistently negative until the tenth period. Contrariwise, the response to LU5M was consistently positive after the third period. The response of LRGDP to LHIVPR was positive in the first period but became negative in the second period and finally assumed positive but fluctuating values till the tent period. Its response to itself and LGHEXP was positive but not steady or the entire period while its response to LU5M was negative for the entire period. The response of LGHEXP to LHIVPR was negative but fluctuating for the ten periods while its response to itself was positive for the entire period. The response of LGHEXP to LRGDP and LU5m fluctuated between positive and negative values with more inconsistencies recorded in LU5M. The response of LU5M to both itself LHIVPR recorded a steady rise of positive values from the first period to the tenth 
period. On the other hand, its response to LRGDP and LGHEXP was a steady decline of negative values from the first period across the entire time horizon.

\subsection{Policy Implications}

From the series of empirical examinations carried out in the study, the following implications are presented as it relates to the Nigerian economy:

- To achieve economic growth, government must increase the budget allocation of the health sector. The analysis has proven that there are strong linkages between health and economic growth as healthier people are more productive, live longer and make important contributions to economic progress.

- HIV/AIDS has positive correlation with economic growth which implies that we cannot assume that HIV/AIDS is the disease of the poor. Therefore, in planning and designing programs for the prevention, care and treatment of those infected with the virus, necessary adjustments should be made.

- Although the ART has been effective, MTCT is still a threat to infants. Policy makers should make it compulsory for all pregnant women to test for HIV so that those positive will start the ART at the early stage of pregnancy to prevent MTCT. This will not only save the lives of the infants but also the lives of the mothers.

\section{Summary, Recommendations and Conclusion}

\subsection{Summary of Findings}

The study empirically examined the relationship and interaction among HIV/AIDS, infant mortality and economic growth in Nigeria utilizing the Vector Error Correction Model. Time series data from 1980 to 2015 was employed to achieve this purpose. Given the influences other economic variables have on HIV/AIDS, infant mortality and economic growth, we incorporated four variables in our analysis. The unit root test conducted using the Augmented Dickey Fuller (ADF) approach reveal that some variables were stationary at levels while others were not. However, all the variables became stationary at first difference. The Johansen cointegration result confirmed the existence of a stable long run relationship among the four variables. The VECM results showed the significance of each variable in relation to other variables. Significant relationships that correlated with economic theory were reported. The Error Correction Mechanism (ECM) that showed the speed of convergence to equilibrium was correctly signed and statistically significant for all variables of interest. The results for the forecast error of variance decomposition revealed that the innovations in the variables are substantially sourced from their own shocks and also contemporaneous shocks in other cointegrating equations. Essentially, it showed the proportion of forecast error variance for each variable that is attributable to own innovation and to innovations in other endogenous variables. The Impulse Response Functions (IRFs) analysis reported the accumulated responses of the variables to their own shock as well as shocks from other variables. Also, the arithmetic root mean stability test established the stability status of all the variables used in the analysis.

\subsection{Policy Recommendations}

In view of the empirical evidence of the empirical assessment of HIV/AIDS, infant mortality and economic growth, the following recommendations are proffered:

- Government at all levels, NGOs, FBOs and other international financial institutions should intensify their efforts to reduce the number of newly infected persons to the barest minimum. This includes but not restricted to education, awareness creation and campaigns in both rural and urban centres to end the silence, indifference and stigma attached to HIV/AIDS in Nigeria.

- The Antiretroviral therapy and drugs should be made readily available for both adults and adolescents that are HIV-positive to reduce the risk of mother-to-child transmission. The WHO in 2009 recommended that ARVs be provided to HIV-positive mothers early in pregnancy, starting at 14 weeks and continuing through the end of the breastfeeding period. They also encouraged longer periods of breastfeeding (12 months) to reduce the risk of HIV transmission and improve the infant's chance of survival.

- Voluntary testing should be encouraged so that every individual is aware of his/her HIV status. This is because so many individuals wait until the symptoms of the virus become visible before they reluctantly go for HIV tests. This reduces their chances of survival as their immunity level is already dangerously low.

- There should be a revision of previous plans and policies aimed at reducing under-5 mortality so that the gains from economic growth can translate into improved welfare for infants. Economic growth was found to have a strong negative relationship with under-5 mortality this implies that increase in economic growth results in a decrease in child mortality.

- To achieve the desirable objective of sustainable economic growth, the health sector should be given a larger budgetary allocation and support as the current government expenditure on health is not making any significant impact. The strong bi-directional linkages between health and economic growth ensure that improvement in health leads to increase in economic growth and vice versa.

\subsection{Conclusion}

From all the empirical analysis and examinations carried out using various econometric approaches to assess the interrelationship amongst HIV/AIDS, infant mortality and economic growth in Nigeria, there is no doubt that HIV/AIDS is a reality in Nigeria and its magnitude poses a real threat to economic growth. With the evidence at hand, we can conveniently say that there is an urgent need for intervention to curb and reverse the spread of HIV. Unless this is done, we would not only record zero but constant negative figures of economic growth. 


\section{References}

Arellano, M., \& Bond, S. (1991). Some tests of specification for panel data: Monte Carlo evidence and an application to employment equations. The Review of Economic Studies, 58(2), 277-297.Available at: https://doi.org/10.2307/2297968.

Arodoye, N. L. (2012). An econometric analysis of the impact of macroeconomic variables stock prices in Nigeria: A vector autoregressive (VAR) model approach. Internal Review of Business and Social Sciences, 1(8), 63-77.

Awofala, A. A., \& Ogundele, O. E. (2016). HIV epidemiology in Nigeria. Saudi Journal of Biological Sciences, 25(4), $697-703$.

Becker, G. S. (1967). Human capital and the personal distribution of income: An analytical approach. Ann Arbor, Michigan: University of Michigan.

Bloom, D. E., \& Mahal, A. S. (1997). Does the AIDS epidemic threaten economic growth? Journal of Econometrics, 77(1), 105-124.Available at: https://doi.org/10.1016/s0304-4076(96)01808-8.

Central Bank of Nigeria. (2014). Statistical bulletin. https://www.cbn.gov.ng/out/2015/sd/2014\%20statistical\%20bulletin\%20contents\%20and\%20narratives.pdf.

Cox, F. D. C. (1997). The AIDS booklet (4th ed.). Boston: McGraw Hill.

Crampin, A. C., Floyd, S., Glynn, J. R., Madise, N., Nyondo, A., Khondowe, M. M., ... Zaba, B. (2003). The long-term impact of HIV and orphanhood on the mortality and physical well-being of children in rural Malawi. Aids, 17(3), 389-397.Available at: https://doi.org/10.1097/00002030-200302 140-00013.

Delacruz, J. J. (2007). An Estimation of the Impact of HIV/AIDS on Economic Growth Using Instrumental Variables. Fashion Institute of Technology, State University of New York, 7th Global Conference on Business and Economics.

Engle, R. F., \& Granger, C. W. J. (1987). Co-integration and error correction: Representation, estimation and testing. Econometrica, 55(2), $251-276$.

Eze, J. I. (2009). Modelling HIV/AIDS epidemic in Nigeria University of Glasgow. Unpublished PhD Thesis. Departement of Statistics, University of Glasgow, Glasgow, UK.

Gillespie, S., Kadiyala, S., \& Greener, K. (2008). Is poverty or wealth driving HIV transmission? International Food Policy Research Institute (IFPRI). Renewal Policy Brief. Retrieved from https://www.ifpri.org/publication/poverty-or-wealth-driving-hivtransmission.

Grossman, M. (1972). On the concept of health capital and the demand for health. Journal of Political Economy, 80(2), 223-255.Available at: https://doi.org/10.1086/259880.

Hamilton, J. D. (1994). Time series analysis. Princeton, New Jersey: Princeton University Press.

Hanmer, L., Lensink, R., \& White, H. (2003). Infant and child mortality in developing countries: analysing the data for robust determinants. The Journal of Development Studies, 4O(1), 101-118.Available at: https://doi.org/10.1080/00220380412331293687.

International Labour Office (ILO). (2005). HIV/AIDS and poverty: The critical connection. ILO programme on HIV/AIDS and the world of work. Retrieved from https://www.ilo.org/aids/Publications/WCMS 120468/lang--en/index.htm.

Iya, I. B., Purokayo, G. S., \& Gabdo, Y. (2012). The effects of HIV/AIDS scourge on production and income among rural households in Adamawa State of Nigeria. Global Journal of Health Science, 4(1), 245-253.

Johansen, S., \& Juselius, K. (1990). Maximum likelihood estimation and inference on cointegration-with appucations to the demand for money. Oxford Bulletin of Economics and statistics, 52(2), 169-210.Available at: https://doi.org/10.1111/j.14680084.1990.mp52002003.x.

Kithinji, L. K. (2015). HIV/AIDS prevalence and labour force participation in Kenya. Unpublished Master's Thesis. University of Nairobi, Nairobi, Kenya.

Levinsoln, J., Shisana, O., McLaren, Z., \& Zuma, K. (2013). HIV status and labour market participation in South Africa. The Review of Economics and Statisticsa, 95(1), 98-108.

Mahy, M. (2003). Measuring child mortality in AIDS-affected countries. Workshop on Hiv/Aids and Adult Mortality in Developing Countries: UNICEF, New York, USA., 8-13 September 2003.

Maijama'a, D., \& Mohammed, B. K. (2013). Impact of HIV/AIDS on economic growth and development in Nigeria. International Journal of Basic and Applied Science, 1(4), 763-772.

Manuelli, R. E., \& Yurdagul, E. (2016). AIDS, human capital and development' department of economics (pp. 126). Calle Madrid: Universidad Carlos III de Madrid.

Masha, I. (2004). The macroeconomic impact of HIV/AIDS in Botswana. International Monetary Fund Working Paper, No. WP/01/80. Research Department an African Department. International Monetary Fund.

McDonald, S., \& Roberts, J. (2006). AIDS and economic growth: A human capital approach. Journal of Development Economics, 80(1), 228250.Available at: https://doi.org/10.1016/j.jdeveco.2005.01.004.

National Agency for the Control of AIDS. (2015). National HIV strategy for adolescent and young people: 2016-2020. NACA. Retrieved from https://www.ilo.org/wcmsp5/groups/public/---ed_protect/_--protrav/_-ilo aids/documents/legaldocument/wcms 532857.pdf.

Nigerian Finder. (2017). History of HIV in Nigeria. Retrieved from https://nigerianfinder.com/history-of-hiv-in-nigeria/.

Ramirez, A., Ranis, G., \& Stewart, F. (2000). Economic growth and human development. World Development, 28(2), $197-219$.

Ravallion, M. (1997). Good and bad growth: The human development reports. World Development, 25(5), 631-638.Available at: https://doi.org/10.1016/s0305-750x(96)00141-6.

Shapiro, R. L., \& Lockman, S. (2010). Mortality among HIV-exposed infants: The first and final frontier. Clinical Infectious Diseases 50(3), 445447.Available at: https://doi.org/10.1086/649887.

Sims, C. A. (1980). Macroeconomics and reality. Econometrica, 48, 1-48.

The World Bank. (1997). Confronting AIDS: Public priorities in a global epidemic. New York, USA: Oxford University Press.

The World Bank. (2016). World development indicator: Nigeria data. Retrieved from http://datatopics.worldbank.org/world-development-indicators/.

Todaro, M. P., \& Smith, S. C. (2012). Economic development (11th ed.). Boston, MA 02116, USA: Pearson Education.

UNAIDS/WHO. (1998). A review of HIV transmission through breastfeeding. Joint United Nations Programme on HIV/AIDS.

Upadhyay, A. K., \& Srivastava, S. (2015). Association between economic growth and infant mortality: Evidence from 13 demographic and health surveys from 36 developing countries. Mumbai, India: International Institute for Population Sciences.

Waziri, S. I., Nor, N. M., Abdullah, N. M. R., \& Adamu, P. (2016). Effect of the prevalence of HIV/AIDS and the life expectancy rate on economic growth in SSA countries: Difference GMM approach. Global Journal of Health Science, 8(4), 212-218.Available at: https://doi.org/10.5539/gjhs.v8n4p212.

WHO. (2005). Infant feeding and HIV transmission. Consultation on nutrition and HIV/AIDS in Africa: Evidence, lessons, and recommendations for action. Geneva, Switzerland: World Health Organization. 